\title{
¿Mujeres modernas para la modernización política? Prácticas y debates sobre la participación de las mujeres en la política, 1955-1966
}

\section{Modern women for political modernization? Practices and Discussions on women's political engaging, 1955-1966}

\author{
Anabella Gorza \\ Centro Interdisciplinario de Investigaciones en Género \\ Instituto de Investigaciones en Humanidades y Ciencias Sociales \\ Universidad Nacional de La Plata \\ Consejo Nacional de Investigaciones Científicas y Técnicas \\ anabellagorza@yahoo.com.ar \\ (Argentina)

\section{Adriana Valobra} \\ Centro Interdisciplinario de Investigaciones en Género \\ Instituto de Investigaciones en Humanidades y Ciencias Sociales \\ Universidad Nacional de La Plata \\ Consejo Nacional de Investigaciones Científicas y Técnicas \\ indivalobra@gmail.com \\ (Argentina)
}

\section{Resumen}

Varias investigaciones han analizado el período entre 1955 y 1966 bajo el prisma de la modernización. Sin embargo, las dimensiones o indicadores de ese proceso a menudo no están claramente establecidos en la 
investigación histórica. Este trabajo se propone analizar cómo los actores políticos de este período utilizaron un discurso que se valió de ciertas dimensiones de la idea de modernización política propuesta por agencias internacionales bajo la órbita de las Naciones Unidas. Estas dimensiones incluyen el acceso de las mujeres a la política en igualdad de condiciones con los varones. Sin embargo, faltan estudios sistemáticos sobre la manera en que se conceptualizó esa idea de modernización política desde una perspectiva de género. En esta vacante temática está incluida nuestra propuesta. Para estudiarlo, nos enfocamos en las estrategias del partido radical -dividido en intransigentes y del pueblo- y en los sectores peronistas.

Palabras Clave: modernización política; mujeres; partidos políticos; políticas gubernamentales; políticas internacionales

\begin{abstract}
Several research studies have analyzed the period between 1955 and 1966 under the prism of modernization. However, dimensions or indicators of that process are often not clearly established in historical research. This paper considers how the political actors of this period used a discourse impregnated with idea of political modernization proposed by international agencies under the orbit of United Nations. These notions included women's access into Politics on equal terms with males. However, there is a lack of systematic studies on political modernization process from a gender perspective. Given de lack of research in this subject this paper is focused on the strategies of radical party-divided in intransigentes and del pueblo- and in Peronist sectors.
\end{abstract}

Keywords: political modernization; women; political parties; government policies; international policies

$$
\propto \tilde{e} \propto
$$

\section{Introducción}

Las investigaciones centradas sobre las primeras décadas de la Guerra Fría coinciden en que la modernización fue un proceso clave del diseño de las políticas internacionales para fogonear una transformación alternativa enmarcada en las lógicas del imperialismo norteamericano y contrapuesto a la vía revolucionaria (Acha, 2012), que, en muchos casos, también se proponía como una forma de modernización. ${ }^{1}$ Elevada a una teoría, se impulsó

1. Vale aclarar que la noción de modernización no estuvo ausente de la retórica soviética y que desde los años 30 se una interpretación sobre el "atraso" económico y social -aunque no menos político- de Latinoamérica -entre otras regiones del denomi-

observa el ímpetu que se dio a la misma, ampliándose a otros ámbitos durante la Guerra Fría. De ese modo, por ejemplo, las llamadas nuevas democracias representaron ejemplos de modernización que emulaban para esa visión, la que había llevado adelante la URSS. Navaith (2000).

En términos de género, además, fue clave esa retórica a fin de evidenciar los lugares por donde avanzaba la igualdad entre mujeres y varones. Valobra y Yusta Rodrigo (2017). No nos concentraremos en este artículo en estas visiones de los años 40 y 60 en las páginas de la prensa comunista vernácula en toda Latinoamérica. Haremos sí, referencias en relación a algunos contactos con las mujeres de los partidos bajo estudio. 
nado Tercer Mundo- a fin de propiciar su desarrollo capitalista y una democracia de estilo occidental. En relación con la modernización política -un proceso visto como evolutivo que desembocaría necesariamente en la democracia-, las teorías suponían que debía existir una racionalización de la autoridad, una burguesía especializada para gerenciar con profesionalización sus actividades, diferenciación de funciones políticas, énfasis en la planificación, desarrollo de estructuras burocráticas para ejecutar nuevas funciones con autonomía y eficacia y aumento de la participación política. ${ }^{2}$ Esa

2. No es posible enunciar completamente la frondosa producción existente sobre el tema, simplemente, sugerir algunos de los textos vertebradores de estas conceptualizaciones sobre modernización política. $\mathrm{La}$ reflexión sobre la modernización política encontró estudios como los de Huntington (1966) y Pye (1979) preocupados por comprender la cultura política e incidir hacia su democratización. Otras vertientes abordaron el problema desde otro ángulo. En la sociología latinoamericana, donde se asistió a un proceso de institucionalización en algunos países como Argentina, Brasil y México, sus abordajes estuvieron principalmente abocados a dilucidar lo que se consideraban problemáticas claves como lo económico y social y se engarzó esa reflexión a la posibilidad del desarrollo, otro concepto fuertemente vinculado al de modernización. Blanco y Jackson (2017). Un papel rector tuvo el trabajo de corte funcionalista de Gino Germani. Blanco (2003). Algunas lecturas de la vertiente cepalina, como las de Cardoso y Faletto, privilegiaron reflexiones sobre lo político, aunque de modo subsidiario a lo socio-económico. Beigel (2006). Jorge Graciarena (1976) se ocupó con detalle del papel incisivo de la cuestión política en la problemática de la modernización. Ansaldi y Giordano (2012). Criticó las teorías sobre la modernización como pesquisadoras del deus ex machina en empresarios, clases medias o burguesías nacionales con vocación hegemónica. Rodolfo Stavenhagen (1981), por su parte, hizo una crítica pormenorizada a las tesis modernizantes en relación con América Latina mostrando cómo sus supuestos erraban en el entusiasmo urbanizador y los efectos modernizadores. Guillermo O’Donnell (1982), por su parte, revisó los supuestos basales de las teorías de la modernización. O’Donnell se inscribió decididamente en el problema de lo político lógica permeó a través de distintos y variados canales y una de sus bases institucionales fueron los organismos internacionales. Sin embargo, la coherencia de ese discurso encontraba límites en la necesidad de que las naciones que "debían modernizarse" fueran, al mismo tiempo, funcionales a los intereses político-estratégicos de Estados Unidos en la región. Así, oponerse al avance del comunismo o de cualquier vertiente política que cuestionara los fundamentos liberales y capitalistas fue el fin último que justificó quebrar los objetivos modernizadores. En la práctica, se estuvo lejos de apoyar proyectos democráticos amplios, beneficiándose ese proceso de gobiernos inestables -ora civiles, ora militares- que se estructuraron -con apoyo de EEUU- sobre la persecución, proscripción y encarcelamiento del otro político; aunque se proclamaran campeones de la democracia. Como veremos, estos intentos de modernización política, tuvieron como telón de fondo la desperonización de la Argentina a fuerza de asedios e interdicciones.

Los estudios sobre mujeres y género en $\mathrm{Ar}$ gentina referidos a la segunda mitad del siglo $\mathrm{XX}$, afirman que las relaciones entre los sexos, anudadas a las nociones de modernización, configuraron parte del diseño social, político, cultural y económico. Feijóo y Nari (1996) ofrecieron una imagen panorámica sosteniendo que, durante los '60, Argentina vivió años de modernización y secularización atravesados por la convulsión política. Para ellas, en la

en pos de dilucidar los vínculos modernización -

democratización. Sus preocupaciones teóricas se sirvieron de frondoso material empírico que reflejaron no sólo el período del Onganiato, su centro de estudio, sino el período histórico más amplio en el que se inscribe, de alternancia cívico militar e estabilidad institucional. La modernización siguió siendo, no obstante, el objetivo que, de alguna forma, se esperaba que neutralizara aquella inestabilidad. 
vida cotidiana de personas de diversas clases sociales, los cambios fueron revolucionarios y la mujer tuvo un papel protagónico mientras que la expansión de las oportunidades públicas en política, educación y trabajo la vincularon a la movilización y radicalización. Una lectura menos optimista respecto de las transformaciones del período la consignó Mala Htun (2003), quien examinó la producción de políticas de género (entre ellas, el divorcio vincular, el aborto y las visiones sobre la familia) y subrayó lo paradójico de que muchas normas "liberadoras" y también liberales respecto de las mujeres se dieron en contextos autoritarios, tal el caso de la reforma civil durante el onganiato. Para Verónica Giordano (2012), durante el período, se impuso una pauta de modernización excluyente: "no sólo de las ideas alternativas, sino también de los sujetos mismos que levantaron esos reclamos alternativos (...) fundamentalmente, de las mujeres y sus demandas autónomas y de autonomía” (p. 272). ${ }^{3}$

Más recientemente, algunos estudios reelaboraron las nociones de modernización socio-cultural y radicalización política, en sintonía con trayectorias historiográficas previas (Cosse, Felitti, y Manzano, 2010). Si bien no proponen una definición de la noción de modernización, hay énfasis distintos respecto de lo que serían sus dimensiones. Para algunas autoras, hay una mayor liberalización de las relaciones interpersonales y radicalización de los cambios (Felitti, 2012). Para otras, en línea con la idea de lo paradójico de Htun, persisten pautas conservadoras en las relaciones de pareja y en los modelos conyugales y familiares y conviven con otras más libérrimas. En conjunto, subrayan las constantes torsiones

3. Esta idea la inscribe en la línea propuesta por Cavarozzi (1982) que analiza las exclusiones del desarrollismo antiperonista.

132 de lo moderno y lo tradicional en el universo representacional de la cultura política. ${ }^{4}$ En ese sentido, otras autoras han dado centralidad al segmento jóvenes en "una profunda, aunque ambivalente, modernización sociocultural en la Argentina de los sesenta" (Manzano, 2010, p. 363). En estos estudios, la modernización es considerada un proceso general en relación con las cuestiones de género, pero no están establecidas sus dimensiones o indicadores salvo en contraposición a lo tradicional o conservador. Asimismo, se utiliza como si hubiera sido un concepto nativo, extendido y empleado por contemporáneos a los hechos estudiados. Empero no se ha problematizado la categoría y la han tratado de modo amplio y literario. En este sentido, no hay estudios sistemáticos sobre el proceso que podría conceptualizarse como modernización política desde una mirada de género ni en relación con las lógicas estatales ni sobre el modo en que lo visualizaron otros actores del sistema político como los partidos. Vale decir, se necesita una reflexión específica sobre la modernización política -si es que el concepto resulta útil para pensar el proceso bajo estudio- $y$ las relaciones de género. En esa zona de vacancia se inscribe esta propuesta.

La categoría modernización, en términos teóricos, puede resultar incómoda e incurrir en un optimismo poco clarificador para comprender el pasado (Acha, 2012). De alguna manera, como señalaba oportunamente Bruno Latour (2016),

"Modernizar" es un término un tanto curioso. Retomando a Gilles Deleuze, podemos decir que es una orden, esto es, un término

4. Aunque la centralidad de la noción de modernización es indudable para comprender el surgimiento de la historieta Mafalda, no hay precisión operativa respecto de ella. Cosse (2014). 
que no viene a describir una situación, que no cumple un objetivo empírico sino un objetivo de movilización: es una suerte de grito desgarrado que vocifera "no hay alternativa, debemos modernizarnos” (p. 17).

Por lo tanto, nuestra investigación analizará cómo aparece la idea de modernización en el discurso político de la época. Esto será abordado en tres apartados. El primero, se ocupa de las propuestas de los organismos internacionales en relación con los derechos políticos de las mujeres. El segundo, analiza el modo en que algunas de esas posiciones delinearon una política en las gestiones de gobierno del período bajo estudio y, a la vez, encontraron sus propios límites en ellas. El último, se ocupa de indagar en las repercusiones que estos temas tuvieron en los partidos políticos, eligiendo para ello las dos vertientes del radicalismo, Intransigente y del Pueblo; y contraponiéndolo a lo sucedido en el peronismo. El corpus documental privilegia las fuentes escritas tales como Informes de organismos internacionales, prensa partidaria y comercial. ${ }^{5}$

\section{Organismos internacionales, mujeres y política}

Los movimientos de mujeres, y particularmente el feminismo, han tenido un tono internacionalista que les permitió convertir las demandas por la mejora de la condición de las mujeres en un parámetro para medir el nivel de desarrollo y modernización de las naciones a partir de los años 50. A su vez, los programas y propuestas de los organismos internacionales impulsaron

5. Agradecemos a la Dra. María Eugenia Bordagaray por el aporte de documentación relevante para la elaboración de este artículo. propuestas sobre derechos de las mujeres. En 1945, impulsada por el comunismo, aunque con participación de vastos sectores, surge en París la Federación Democrática Internacional de Mujeres (en adelante, FDIM). Su fin era convertirse en vocera de la paz, erradicar al fascismo y mejorar las condiciones de vida de las mujeres tomando como modelo a la URSS y a las nuevas democracias. En 1954, la FDIM perdió el status consultivo en la Organización de las Naciones Unidas (en adelante, ONU), en una fuerte avanzada contra las instituciones consideradas "pantallas del comunismo". Esta confrontación sólo fue posible debido a que la maniobra que exponía la relación FDIM URSS se hizo patente frente a la omisión de la que relacionaba la ONU y la Comisión Interamericana de Mujeres (en adelante, CIM) con EEUU (Haan, 2010). Con todo, la CIM, en particular, no obstante ser financiada por fondos norteamericanos, habría tenido un papel crítico sobre las políticas estatales -en particular en los años '20 y '30 y hasta los '40 (Miller, 1991, p.192) -sobre la sanción del voto femenino (Towns, 2010).

Por su parte, la Comisión sobre la Condición Jurídica y Social de la Mujer de la ONU promovía, desde su fundación en 1947, encuentros regulares para lograr un marco normativo e indicadores de evaluación de la aplicación de leyes, acuerdos y convenciones sobre las condiciones de progreso de las mujeres. Se formularon los parámetros sociales y políticos sobre los que las naciones del tercer mundo debían trabajar a fin de alcanzar mejoras en las condiciones femeninas. En relación con los de orden político, se establecía la participación en la vida pública, en general, y en particular, en ámbitos de gobierno con desbalances intergenéricos.

Además, la CIM, primer organismo intergu- 
bernamental en nuclearse en pos de los derechos femeninos en los estados americanos, también impulsaba un programa sobre derechos políticos. La interrelación con la Comisión sobre la Condición Jurídica y Social de la Mujer de la ONU fue estrecha y la CIM presentó ante ella numerosos informes que recuperaban la particular situación de las americanas. En 1960, la CIM afirmaba: "En el presente, cuando los derechos civiles y políticos han sido otorgados a la mujer en casi todas las Repúblicas de América, comienza la tarea mucho más difícil y extensa de hacer uso pleno de esos derechos" (CIM, 1966, p. 12). La noción de modernización política no estaba integrada al vocabulario de la CIM, en el que sí aparecía la de desarrollo. Había, sí, una idea de rémoras que había que superar, una idea de lo antiguo y lo nuevo:

bajo un signo de los tiempos nuevos, la Condición Social y Económica de la Mujer, punto central de la Agenda.

(...) Condición Social y Económica de la Mujer Trabajadora, más que un modernismo, es una proa inquietante en mares poco explorados. Es la tentativa actual de alterar los valores tradicionales, cambiar de lugar el fiel de la balanza e introducir un equilibrio nuevo en los destinos humanos (CIM, 1960, p. 13).

Se consideraba, por tanto, que reconocidos los Derechos Políticos en casi todos los países americanos, la CIM debía "propender a la Educación Cívica de la Mujer a fin de interesarla en el bien público y en el ejercicio de sus derechos" (CIM, 1960, p. 37). Ello debía reforzarse no sólo en relación con el voto sino también en su participación en los cargos públicos tanto en los que se alcanzaban por elección como por nombramiento. También, debía pro- piciarse su participación en Asambleas Internacionales y en Conferencias y Congresos del Sistema Interamericano (CIM, 1960, p. 38).

Para la CIM o la ONU, esos derechos presentaban distintas dimensiones que se realizarían en diferentes etapas:

\section{Primera Etapa}

1. Sanción de leyes de derechos políticos para ejercer la faz activa (voto) como pasiva (elegibilidad)

\section{Segunda Etapa}

1. Educación del electorado femenino tanto en su alfabetización en general educación cívica y política, en particular, en ámbitos de educación primaria y secundaria

2. Promoción de las mujeres en cargos públicos: elegibles: tanto legislativos y ejecutivos en el nivel nacional, provincial como municipal por nombramiento: políticos, judiciales, administrativos y diplomáticos tanto en el nivel nacional como internacional.

3. Participación de las mujeres en la vida pública en: Agrupaciones civiles y sociales (tanto laicas como religiosas): ligas de amas de casa, clubes de madres, etc. Agrupaciones profesionales y grupos de presión. Agrupaciones de educación cívica de las mujeres.

Si tomamos en cuenta las dimensiones que propusieron las teorías vinculadas a la modernización política, el énfasis de los organismos internacionales estuvo en la eficacia y aumento de la participación política y otras aristas fueron subsidiarias de ésta. En conjunto, ambos organismos tuvieron como fin perfeccionar la democracia en pos de la efectivización de la incorporación femenina tras la sanción de 
las leyes de derechos políticos en casi todos los países de la región. Para ello, profundizaban relaciones con los gobiernos y agrupaciones femeninas de sectores privados para que se comprometieran en la educación cívica y formación de nuevas lideresas.

Las argentinas tuvieron papeles relevantes en ambos organismos, incluso, la CIM estuvo dirigida por la militante radical Ana Rosa Schliepper de Martínez Guerrero (1939). Si bien en agosto de 1949, en una Asamblea Extraordinaria, la Primera Dama argentina fue presidenta honoraria, durante el peronismo, hubo una deriva del panamericanismo femenino más bien retórica (Valobra, en prensa). La presencia de las agencias internacionales se haría más patente después del golpe de 1955. El gobierno de Frondizi estableció relaciones con la ONU y la CIM en pos de aggiornar la temática de las mujeres y la política. Muchas de estas nociones permearon en otros grupos. Carlos Altamirano (1998) ha señalado cómo el discurso del desarrollismo, central en el frondizismo, tuvo amplia circulación en otros sectores:

En la Argentina, el término desarrollismo cristalizó con un significado particular, asociado al gobierno de Arturo Frondizi y al movimiento ideológico y político que lo tuvo como orientador junto con Rogelio Frigerio. Pero lo cierto es que la idea del desarrollo fue, como en el resto de los países latinoamericanos, el objeto de referencia común para argumentos, análisis y prescripciones distintas dentro del pensamiento social y económico argentino (p.79).

En línea con ello, a continuación, analizaremos cómo algunas de estas ideas fueron abordadas desde los gobiernos del periodo y cómo fueron incorporadas por integrantes de los partidos radical, en sus dos vertientes, y peronista.

\section{Mujeres y política: de las propuestas de campaña a los discursos de la gestión}

Para comprender cuál fue la concepción de la modernización política en relación con las mujeres durante los gobiernos desarrollistas, es necesario comenzar por las propuestas de la intransigencia radical encabezada por Arturo Frondizi. Estas propuestas se plasmaron en el contexto previo a su llegada a la presidencia y, durante su gestión, se hicieron visibles en la creación de dependencias estatales dedicadas a las mujeres. Sin duda, un corpus privilegiado para apreciarlas lo constituye la revista Quésucedió en 7 días (en adelante Qué), una usina de ideas que tuvo sustento en las investigaciones que llevaba adelante el Centro de Investigaciones Nacionales (en adelante, CIN) propiciado por la línea intransigente del radicalismo. Éste, dividido en distintas secciones, tuvo una dedicada a la condición femenina y fue dirigida por Blanca Stábile. En la revista Qué, una columna comenzó a cobrar relevancia y a volcar el cúmulo de información obtenido en el CIN. En otros estudios hemos señalado las generalidades del caso (Valobra, 2013), aquí nos interesa considerar qué visión se desplegó sobre la modernización política en ese corpus.

A pesar de que las investigaciones han subrayado que la noción de modernización es una categoría nativa, en este corpus no lo es, pues no figura como tal. Sí aparece la noción de moderno/a como adjetivación: "sociedad 
moderna", 6 "vida moderna", "Estado moderno", "mundo moderno", "partido moderno", "modernas escuelas profesionales". ${ }^{8}$ La noción "mujer" adjetivada como "moderna", tan claramente asociada por las investigaciones de corte cultural sobre el período, no se constata en esta fuente donde apenas hay un par de menciones. ${ }^{9}$ Tampoco el libro de Blanca Stábile, $L a$ mujer en el desarrollo -sin duda, un balance de su gestión- aborda estrictamente el problema desde esta noción, y se centra en la de desarrollo.

En los documentos, son conceptos claves los de participación, vida pública, capacidad de las dirigentes y capacitación de las ciudadanas, formas especulares de las nociones divulgadas

6. Por un programa femenino (26 de marzo de 1957). Qué sucedió en 7 días. p. 22. Archivo personal de Adriana Valobra (APAV), La Plata. Allí se afirmaba, "Las mujeres necesitan bastarse a sí mismas en una sociedad moderna, a fin de no depender del matrimonio para mantenerse".

7. Panorama nacional. La mujer en la vida moderna ( 3 de febrero de 1959). Qué sucedió en 7 días. APAV, La Plata. Allí, se refería a la visita de Ana Figueroa de la OIT junto con Blanca Stábile y Clotilde Sabattini.

8. Modernas escuelas profesionales para las jóvenes argentinas (11 de junio de 1957). Qué sucedió en 7 días. p. 22-23. APAV, La Plata. Se refiere a la tejeduría industrial, electricidad, entre otras. Específicamente, considera "Ampliar y modernizar los estudios en las escuelas profesionales para proveer a las adolescentes de las mejores y más variadas armas con que luchar por el sustento en forma eficaz, interesante y bien remunerada". Trabajo femenino, factor de progreso social (19 de marzo de 1957). Qué sucedió en 7 días. pp. 16-17. APAV, La Plata. Un ítem se llama "Precursoras de una moderna asistencia social (habla del servicio social).

9. ¿Debe pagar la mujer el pecado de Eva? (6 de agosto de 1957). Qué sucedió en 7 días. p. 142. APAV, La Plata. El artículo se refiere al Papa y a la iglesia, la moda y las restricciones sobre las mujeres. Se afirma, "La moda no es mala, pero no puede ser el centro de interés de las mujeres". En el epígrafe de una foto se escribe: "La Mujer Moderna. La moda no es cosa mala”. por los organismos internacionales. Estas ideas aparecían en relación con la idea de que existía una sociedad con cierto grado de modernización, pero no lo suficientemente acabada al no incorporarse las voces femeninas; un Estado moderno, pero no completamente tal si las mujeres no eran centro de sus preocupaciones; un partido no lo suficientemente moderno si no se consignaba la presencia plena e igualitaria de las mujeres. Vale decir, la modernidad era concebida como parte de un proceso de modernización inacabado y sólo se lograría plenamente cuando se diera la incorporación de las mujeres aún ausentes o presentes en cupos limitados.

La revista Qué se preocupó por evidenciar un nuevo perfil político entre las mujeres que asumían protagonismo en ese momento, las que, no casualmente, tenían entre sus condiciones títulos universitarios o terciarios, desarrollos profesionales o antecedentes en la gestión institucional tanto pública como privada, muchas con fines sociales.

Parte del interés de esa modernización política a la que tácitamente se aludía estuvo volcado a subsanar lo que se concebía como desbalances regionales: diferencias entre las mujeres en las provincias y en las grandes capitales; entre el campo y las ciudades; y también, diferencias entre niveles educativos, profesionales, etc.

Tanto la participación en partidos y sindicatos como en la función pública, se fundaron en la formación política y la racionalización jurídica e institucional. La formación política debía desplegar una pedagogía altruista temperada por mujeres de partidos políticos diversos que se sobreponían a sus diferencias en pos de un bien común superior: sustraer a sus connacionales del estado de retraso y desigualdad. En 
relación con la racionalización jurídica e institucional, se esperaba que las normativas garantizaran derechos y permitieran organizar espacios propios en la gestión estatal.

Entonces, si tenemos en cuenta las dimensiones e indicadores propuestos por los organismos internacionales, cabe consignar que en la prensa cercana al radicalismo se privilegió la dimensión de la eficacia y aumento de la participación política, desagregándose con cierto detalle la cuestión de la participación política y sindical así como ámbitos de la sociedad civil primando la relevancia de la formación.

La llegada de Frondizi a la presidencia tras las elecciones de febrero de 1958 fue el momento propicio para llevar adelante las iniciativas formuladas previamente en relación con las mujeres. Durante su gobierno, hubo un intento de desarrollar estructuras burocráticas para ejecutar nuevas funciones especialmente dirigidas a la mujer, el intento de gerenciar con profesionalización sus actividades especializadas y la procura de una eficacia y aumento de la participación política femenina. Sin embargo, como veremos, esas dimensiones tuvieron dificultades para su consecución más allá de la importancia de ciertos hitos institucionales y una retórica proactiva.

En efecto, inmediatamente de asumir, se dio lugar al primer acto de institucionalización estatal: dentro de la cartera de trabajo, se creó la Dirección Nacional de Seguridad y Previsión Social de la Mujer (en adelante, Dirección), dirigida por Blanca Stábile. Durante esta gestión, la concordancia con las líneas de organismos internacionales es tan importante que en los Boletines de la CIM se mencionan en varias oportunidades las acciones de la $\mathrm{Di}^{-}$ rección. Además, las autoridades de la CIM fortalecen el vínculo con viajes y entrevistas; ${ }^{10}$ mientras la ONU organiza la reunión de la Comisión Social y Económica en Buenos Aires (marzo, 1960).

Una de las tareas más importantes que encaminó la Dirección fue la formativa a través de cursos vinculados a lo que se consideraba un aspecto descuidado de la formación política de las mujeres, la sindical, sector influenciado profundamente por el peronismo y brazo clave de confrontación durante el período. Se impartieron cursos de Educación Gremial; Relaciones Humanas en el Trabajo y Principios modernos para la organización de un sindicato y Adiestramiento para mujeres maduras (Stabile, 1961, p. 22).

No obstante, la Dirección no contaba con uno de los indicadores centrales de la modernización: autonomía económica dada por la partida presupuestaria. Por ello, su función no se concibió como intervención directa sino como articuladora de distintas esferas estatales y privadas para dar respuestas concretas a las necesidades detectadas en casos individuales (Valobra, 2013). De allí, que todas las actividades que realizaba, incluidas las capacitaciones, seguimiento de casos, entre otras, eran ad honorem. A la vez, se entablaron relaciones con agrupaciones pre-existentes de corte católico a fin de contar con entornos institucionales que pudieran amortiguar las tareas sin costos para el Estado. Esto impuso un perfil muy particular a las intervenciones de la Dirección que supusieron lecturas contrarias a las que se habían propuesto desde Qué. Ello se hizo elocuente cuando, a instancias de Naciones Unidas, la Dirección organizó el I Seminario Nacional

10. Hacia una cooperación entre las mujeres de Latinoamérica (27 de mayo de 1958). Qué sucedió en 7 dias. p. 2. APAV, La Plata. 
sobre la Participación de la Mujer en la Vida Pública en Buenos Aires, en diciembre de 1960. Al concentrarnos en uno de los cuatro tópicos abordados, La mujer en la política, se aprecian diferencias entre las recomendaciones internacionales y las apropiaciones locales. $\mathrm{La}$ participación de las mujeres en la vida pública no debía descuidar su misión social inclaudicable como esposa y madre (Felitti, 2012, pp. 61-62). Por ello, era recomendable que actuaran en espacios compatibles con la familia y que, en todo caso, denunciaran las dificultades que su ingreso laboral o en la vida cívica acarreaba con la domesticidad (Stabile, 1961, pp. 207-208). Políticamente, y también con fuertes referenciamientos religiosos, se invitaba a las que tuvieran "más tiempo libre", que fueran "más aptas y mejor preparadas" a ingresar a la política y representar a sus congéneres. Estas prevenciones se formulaban en relación directa con la experiencia de representación femenina del gobierno peronista que descalificaban por lo que consideraban su falta de profesionalismo y exceso de fanatismo (Stabile, 1961, pp. 233-234). Se las visualizó como emblemas de una vieja forma de hacer política en la que se exacerbaban, merced las designaciones de género, la irracionalidad, la movilización masiva y acrítica y el sentimiento y fanatismo. Se consideraba que, con esas características, se había logrado la reelección a Perón la primera vez que las mujeres votaron y que, además, representaban valores tradicionales y réprobos en la figura de Evita y sus "sucesoras"-legisladoras, dirigentes del Partido Peronista Femenino, partícipes de la Fundación Eva Perón-, mujeres sin la formación adecuada según estas visiones, para llevar adelante la empresa que se les encomendaba.

Sin embargo, paradójicamente, ello no impidió la concreción de instancias de cooperación entre mujeres de diferentes partidos políticos, que incluyeron a las peronistas, ni tampoco que entre algunas de estas últimas emergiera un discurso que se hiciera eco de las ideas de modernización política, permitiéndoles ejercer una crítica sobre su propio partido. Esa apertura se hizo patente en relación con algunas figuras que destacaban por su perfil profesional o por el potencial de su intervención. Este es el caso de Lucila de Gregorio Lavié, activa en la gestión de la Secretaría de Trabajo y Previsión, desde 1944, en la Comisión Pro Sufragio Femenino. ${ }^{11}$ Colaboró con la Dirección dirigida por Stábile, ad-honorem, dictando cursos de capacitación como el de Educación Gremial. A la vez, fue observadora en el Seminario de la Mujer en la vida Pública (1960). También, Inés Dighian, delegada e integrante de una agrupación sindical en el rubro comercio, ${ }^{12}$ participó en la reunión de la ONU en Buenos Aires, antes mencionada, y en el comité organizador del Seminario Nacional... de diciembre, donde fue becaria sindical por la Embajada de Israel (Stabile, 1961, p. 24). ${ }^{13}$

11. Sobre esta cuestión, véase: Bianchi (1986) y Lobato (2003, p. 39). Lucila de Gregorio Lavié, como abogada, desarrolló su experticia en derechos de las mujeres y escribió varios volúmenes. Entre sus obras se encuentran: De Gregorio Lavié (1947 y (1948).

12. Había tomado cursos organizados por el Partido Socialista y, en 1959, fue becada por el Departamento de la Mujer del Ministerio de Trabajo y Previsión para concurrir al Encuentro Internacional de Mujeres que tuvo lugar ese año en Israel. Entrevista a Saúl Buzeta (h) (hijo de Inés Dighian), realizada por Anabella Gorza, 11 de marzo de 2014.

13. No debemos descartar que la llegada de Frondizi a la presidencia se produjo merced a un pacto con el peronismo. Un ejemplo lo constituye la edición de Linea Dura (1957-1958), un periódico creado para sostener la línea del pacto. Algunos de sus integrantes, en años posteriores, integraron el Movimiento de Integración y Desarrollo; desprendimiento de la UCRI, creado en 1963, para sostener las ideas desarrollistas y organizado 
Las lecturas que se han hecho sobre estas intervenciones catalogaron sus resultados como conservadores (Barrancos, 2007, pp. 219-220) y elitistas (Henales y Del Solar, 1993, p. 36), evidenciando que el rol de la mujer consistía en un problema relevante para llevar adelante un proyecto de modernización del Estado -siguiendo los stándares internacionales-, pero que no terminaba de concebir la autonomía de las mujeres de las supuestas tareas naturales que les correspondían, aunque, de manera paradójica, se las impulsara a actuar en la vida pública.

Poco después de este Seminario Nacional, el 27 de febrero de 1961, Argentina suscribió la Convención sobre los derechos políticos de la Mujer (1953) (ley 15.786). Esta expresaba en sus primeros articulados que las mujeres tendrían derecho a votar en todas las elecciones; que serían elegibles para todos los organismos públicos electivos y que tendrían que ocupar cargos públicos y ejercer todas las funciones públicas establecidas por la legislación nacional; en todos los casos en igualdad de condiciones con los varones y sin discriminación alguna. Si bien en Argentina las mujeres votaban, en principio, en igualdad jurídica; los otros aspectos estaban relegados, lo cual se explica no sólo como parte de la inestabilidad política sino como expresión de conflictos de género, como lo evaluó oportunamente Blanca Stábile (1961, pp. 82-83). ${ }^{14}$

Tras la caída de Frondizi, y la breve presidencia de Guido, asume el gobierno Arturo Illia

por Frondizi y Frigerio. María Granata, directora del periódico, consideraba que "el gobierno 1958-1962 representaba Peronismo + Industria Pesada”. Granata, entrevista de Marta Cichero. Véase: Cichero (1992, p. 233).

14. Véase también: Felitti (2012, p. 62). con un escaso margen electoral. Sin embargo, ya desde su campaña, Illia mostró un perfil abierto a la reflexión sobre la temática de las mujeres. Bajo el título "Yo prometo a las mujeres", se publicó una entrevista que le realizaron ocho militantes. ${ }^{15} \mathrm{La}$ ronda de preguntas se abrió inquiriendo sobre las causas por las que los partidos continuaban relegando a las mujeres de las posiciones electivas. Illia consideró que había una modalidad predominantemente masculina pues, en los distritos mayoritariamente con afiliados varones, ellos dominaban el padrón; pero donde las mujeres se destacaban, como en Córdoba, se proyectaban; como lo hacía la Dra. María Teresa Merciadri de Morini. No obstante, Illia consintió en que la baja participación era una rémora. ${ }^{16}$

Ya electo Illia, desde Qué se fustigaban las intervenciones de su esposa. A ella y a su grupo, las denominaban "Las señoras gordas", expresión acuñada por el legislador Perette durante un debate parlamentario en el que un grupo de mujeres confrontaron desde el palco. Esta manera de calificarlas se proponía deslegitimar sus acciones; sin embargo, durante la gestión de Illia (1963-1966), varios de los programas internacionales, incluso algunos comenzados durante la gestión de Frondizi, continuaron y se reforzaron. ${ }^{17}$

15. Estas se inscribieron bajo la institución Club Argentino de Mujeres y eran Alcira Mendiondo de Brezano Fontana, su presidenta, María D. Founrouge de Saguier (conservadora), Clotilde Sabattini (UCRI), Elsa Chamorro y Celina R. de Martínez Paiva (PJ), Alicia Lozza de Loredo (Partido Demócrata Progresista), Lidia Valente de Pérez Tort (UDELPA), y Haydée Frizzi de Longoni (bengoísmo).

16. (19 de junio de 1963) La Razón. p. 4. Hemeroteca del Congreso de la Nación (HCN), Buenos Aires.

17. En efecto, en la política sanitaria uno de los temas centrales era el papel de las mujeres. Así, el programa lanzado en 1961, “Argentina 25", realizado a partir de 
A lo largo de las gestiones radicales, la retórica de los organismos internacionales se expresó en distintas propuestas vinculadas al desarrollo político. Como señalamos al comienzo, la creación de estructuras burocráticas como la Dirección y de un grupo de profesionales especializadas, que podríamos vincular con las recomendaciones de aumentar la participación de las mujeres en los cargos de designación, no fue acompañada con la autonomía que implica un presupuesto propio. Sin embargo, la presencia de las mujeres en puestos tales, no era nueva. Lucila de Gregorio Lavié, como dijimos, estuvo en la División de Trabajo y Asistencia de la Mujer dependiente de la Dirección General de Trabajo y Acción Social durante la gestión de Perón, entre 1943 y 1945, y Cristina M. de Aparicio fue directora de la Dirección Nacional de la Mujer durante la Revolución Libertadora. Además, ninguno de los dos gobiernos se caracterizó por un aumento de la representación parlamentaria femenina, punto importante de la modernización de las instancias políticas que tenían los organismos internacionales, ni mucho menos, se acercó al porcentaje habido durante los gobiernos peronistas. Vale decir, existieron iniciativas que, empero, no alcanzaron las demandas de equiparación que se proponían. A continuación, analizaremos el modo en que estas cuestiones fueron discutidas internamente en los partidos.

convenios con la Organización Mundial de la Salud y Unicef a través de la OPS (Organización Panamericana de la Salud) para brindar cursos de adiestramiento para auxiliares de enfermería -incluso en servicio-continuó durante aquel gobierno llegando a casi formarse diez veces más que en los años precedentes. El papel de la enfermería, por cierto, había sido un tema impulsado por la revista Qué; y también abordado en el gobierno de Frondizi.

\section{De cómo modernizar los partidos: formación de cuadros femeninos y promoción de mujeres dirigentes}

En este apartado, rastrearemos los debates en la UCR, tanto Intransigente (en adelante, UCRI) como del Pueblo (en adelante, UCRP), en torno a algunas de las dimensiones del proceso de inclusión política femenina, y las compararemos con las suscitadas en el peronismo. Cabe mencionar que los términos en los que se plantea el debate interno no incluyen, tampoco, la noción expresa de modernización política, sino dimensiones que se asociaron a ella en ese contexto histórico. Puntualmente, queremos llamar la atención sobre el hecho de que aunque los organismos internacionales no detallaban con precisión de qué modo debían traducirse internamente las propuestas, en el caso de las radicales, además de las intervenciones en la gestión, ellas reclamaron en sus partidos, reapropiándose de los lineamientos internacionales.

Recordemos que el Partido Radical está asociado a los derechos políticos de las mujeres en tanto fue su diputado Rogelio Araya quien, en 1919, presentó el primer proyecto en la cámara de diputados de la Nación; aunque la UCR modificó recién en 1931 sus estatutos para dar lugar a la participación femenina en tareas de propaganda. No obstante ello, el partido contó con numerosas dirigentes que procuraron organizar a las mujeres desde sus inicios y que reclamaron su reconocimiento y promoción partidaria y cargos electivos, con magros resultados (Valobra, 2010).

Paradójicamente, mientras que las mujeres en el gobierno intransigente y sus alianzas con las católicas exponían un estancamiento en la traducción local de las lógicas interna- 
cionales; en la UCRI, se intentaba impulsar la participación femenina. Como veremos, en sus reclamos aparecen como categorías claves la exigencia de cargos de dirección o responsabilidad dentro del partido y los de gestión estatal así como la idea de igualdad. Según una de las más destacadas dirigentes del período, María Teresa Muñoz de Liceaga, economista, militante en la sección 6 de Capital, y futura diputada:

la UCR (...) no admite diferencias de sexo en la aplicación de sus ideas. En los padrones del partido, el $30 \%$ de los afiliados son mujeres y esa proporción llega al 50\% en algunos distritos. En los comités parroquiales, cuyas comisiones directivas están formadas por 12 miembros, el 20\% de las direcciones es femenino. ${ }^{18}$

Evidentemente, los porcentajes no hablaban de una paridad, aun cuando ésta pudiera ser estipulada. Por ello, Liceaga sostenía también:

los prejuicios ambientales son los que impiden a la mujer una vida política más activa. El hombre desconfía de las posibilidades de la mujer y menosprecia su contribución a la vida pública, aunque a veces acepte que una de nosotras pueda destacarse. Consecuencia de ello es que todavía se rehúse a la mujer el papel directivo que podría desempeñar con gran responsabilidad. Hemos obtenido el voto, pero aún no se nos ha dado ingerencia [sic] activa en ningún organismo del Estado. ${ }^{19}$

Liceaga se hacía eco de los indicadores in-

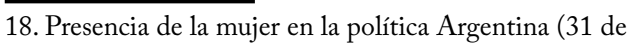
julio de 1956). Qué sucedió en 7 días, pp. 30-33. APAV, La Plata.

19. Presencia de la mujer en la política Argentina (31 de julio de 1956). Qué sucedió en 7 días, pp. 30-33. Buenos Aires. APAV, La Plata. ternacionales para analizar la situación de las mujeres en la política. En la Comisión femenina del Centro de Investigaciones Nacionales, Blanca Stábile proponía un "Método científico para realizaciones concretas". ${ }^{20}$ Pero ésta no era la única que fomentaba esa participación femenina, también, lo hacían la Organización femenina radical intransigente (OFRI dirigida por Emilia Tortorelli y Olga Ponce de León), la Asociación Hipólito Yrigoyen de Córdoba y la Organización Nacional Femenina M. Lebensohn. ${ }^{21}$

Juan Ovidio Zavala, abogado puntano que tuvo una labor decidida en varias carteras de gobierno durante la gestión de Frondizi, autor de un libro llamado Racionalización y desarrollo (1963), era taxativo:

la sociedad moderna ha postergado a las mujeres en la jerarquía de las funciones. Hay desigualdad. La mujer tiene la parte más dura y el hombre tiene honores y privilegios. El Estado moderno no puede mantener este esquema. La cláusula de la Carta Orgánica del Mir que reserva el 30\% de los cargos a las mujeres, proyecta al partido como un partido moderno, pero no resguarda a la mujer, por cuanto mantiene el criterio de desigualdad. Cuando no sea necesaria esa cláusula, cuando se le haya olvidado, seremos realmente un partido moderno, donde la ciudadanía estará representada en un pie de igualdad. ${ }^{22}$

20. Un plan de progreso material y espiritual para medio país (7 de enero de 1958). Qué sucedió en 7 días, p. 28. Buenos Aires. APAV, La Plata.

21. Una organización que fomenta la militancia política de la mujer (4 de febrero de 1958). Qué sucedió en 7 días, p. 28. Buenos Aires. APAV, La Plata.

22. El hogar y la militancia cívica (7 de octubre de 1964), Qué sucedió en 7 días, p. 36. APAV, La Plata. 
Según las investigaciones de Edith Gallo (2000), ya el 26 de enero de 1957, el Comité Nacional -encabezado por Oscar Alende y reunido en Rosario- dictaminó una Resolución sobre la mujer y la política (p. 112). La delegada de San Luis, Marcela Gatica de Vilches luego, sucesora de Stábile en la Dirección- fue vocera al disertar sobre La mujer en el partido. ${ }^{23}$ Como corolario, en esa Convención se propuso el Estudio y organización de un plan de incremento de la actividad femenina a través de la creación de juntas regionales y el aumento de mujeres en cargos de representación.

En la UCRP, también, las mujeres conformaron un núcleo que confrontó tanto en la interna partidaria como con el gobierno de Frondizi. E1 5 de julio de 1956, las unionistas tuvieron su encuentro en Santa Fe, presidido por Clorinda Pinasco de Busaniche. ${ }^{24} \mathrm{El}$ mismo se enmarcó en la reforma del Estatuto de los Partidos Políticos donde la Junta Consultiva Nacional sugería una normativa ordenadora acotada que fiscalizara la declaración de principios democráticos, programas de acción, carta orgánica y una denominación que no invocara nombres personales (en alusión al partido peronista) ni se diferenciara de otras (en referencia al Partido Peronista Femenino). En ese contexto, la reunión de las mujeres cobraba sentido para revitalizar su papel interno. Según una de las más destacadas unionistas, Florentina Gómez Miranda, las radicales ocupaban, al menos, un

23. Finalizó hoy su labor en Rosario el Comité Nacional de la UCR (27de enero de 1957). El Litoral. Recuperado de http://www.santafe.gov.ar/hemerotecadigital/ diario $/ 24879 /$ ?page $=1 \& z 1=4 \& x p=-1509 \& y p=-1199$

24. Unión Cívica Radical. Congreso Nacional de Mujeres Radicales (5 de julio de 1956). El Litoral, p. 5. Recuperado de: http://www.santafe.gov.ar/ hemerotecadigital $/$ diario $/ 24694 /$ page $=5 \& z l=4 \& x p=-$ $1255 \& y p=-847$

142 tercio del padrón radical. En ese encuentro en Santa Fe,

Todas las tareas las realizaron solas, sin ninguna ayuda masculina. La asamblea trató diversos tópicos: la función de la mujer dentro del partido, los problemas de las trabajadoras, el enfoque femenino de la ley de profilaxis, la educación sexual de la juventud y la contribución de la mujer a la recuperación del país. ${ }^{25}$

Así, en la UCRP, durante la Convención de la Provincia de Buenos Aires (Avellaneda, 6 y 7 de septiembre de 1958), se estableció la resolución sobre la participación "atenta a la necesidad de obtener dentro de la vida partidaria la total integración de sus cuadros". Se solicitó al Comité de la Provincia que éste hiciera "conocer a los organismos partidarios la necesidad de incorporar en forma activa la labor femenina a la acción permanente" de la UCRP. ${ }^{26}$ En el Congreso provincial (Tandil, 1958), presidido por María Roldán de Foulkes, el reclamo seguía vigente: se conformó un Comité Femenino bonaerense que tendría reuniones mensuales y asambleas periódicas a fin de encaminar la participación femenina. ${ }^{27}$ Este Comité, encabezado por Matilde R. de Amigo, fue muy

25. Presencia de la mujer en la política Argentina (1 de julio de 1956). Qué sucedió en 7 días, pp. 30-33. APAV, La Plata.

26. Unión Cívica Radical Del Pueblo, H. Convención de la Provincia de Buenos Aires, Reunión de la H. Convención, Avellaneda, 6 y 7 de septiembre de 1958 p. 4. Archivo personal de Eduardo Volonté (APEV), Ayacucho (Consultado en 2017 por la Dra. María Eugenia Bordagaray y facilitado para este artículo).

27. Unión Cívica Radical Del Pueblo, Informe del Comité de la Provincia de Buenos Aires, Buenos Aires, 1959.

APEV, Ayacucho (Consultado en 2017 por la Dra. María Eugenia Bordagaray y facilitado para este artículo). 
crítico del gobierno de Frondizi. ${ }^{28}$ Tampoco ahorró reclamos internos. En 1961, envió una carta al Presidente de la UCRP consignando que en virtud de la acción que desarrollaban las radicales del pueblo, la Comisión Femenina

vería con sumo agrado la inclusión de correligionarias en las listas de la próxima elección interna. Creemos necesario crear o fortalecer una conciencia uniforme en tal sentido, capaz de estimular la militancia femenina en las filas partidarias y de retribuir su esfuerzo y eficacia, con cargos de responsabilidad. ${ }^{29}$

Como señalamos, durante estas gestiones radicales, la proyección de mujeres en los puestos de gobierno con cierta envergadura fue importante simbólicamente destacándose Stábile y Clotilde Sabattini en el Consejo Nacional de Educación, pero no se incrementó respecto del período de gobierno de la Revolución Libertadora.

Ahora bien, ¿qué sucedía en el caso de las peronistas que habían tenido una organización exclusivamente femenina, el Partido Peronista Femenino (en adelante PPF), que se encon-

28. Convención de la Provincia de Buenos Aires de la Unión Cívica Radical del Pueblo, Comisión femenina, La Mujer Radical Y La Ley De Energía, septiembre de 1960, firmado por Matilde R. de Amigo. APEV, Ayacucho (Consultado en 2017 por la Dra. María Eugenia Bordagaray y facilitado para este artículo).

29. Comisión Femenina de la Unión Cívica Radical Del Pueblo Provincia De Buenos Aires, Carta al Presidente del Comité de Partido, 5 de mayo de 1961. APEV, Ayacucho (Consultado en 2017 por la Dra. María Eugenia Bordagaray y facilitado para este artículo). Estas propuestas se reforzaron a posteriori, pues, según consigna Edith Gallo, a comienzos de noviembre de 1962, la Dra. Celia González presentó en el Comité Nacional de la UCRP un trabajo de investigación: "La problemática de la Mujer en la vida política”. Gallo (2000, p. 142). traba proscripta desde 1955? Los discursos dominantes adjudicaban al peronismo características antidemocráticas. ${ }^{30} \mathrm{De}$ allí, se deducían sus cualidades antimodernas. Según señalamos, durante la gestión de Stábile, se cuestionó el modo de participación femenina en el peronismo y se intentó frenar su masividad, procurando disciplinarla y encauzarla. Ahora bien, ¿es posible que hubiera contacto entre las peronistas con los discursos internacionales que se proponían esa modernización política de las mujeres? ¿Qué espacio hubo para su emergencia en un contexto en el que el peronismo, atravesado por intensas luchas internas, se vio abocado a la pelea por la legalidad de su estructura partidaria, la reorganización de la misma, los conflictos sindicales y el retorno de Perón?

Recordemos que el peronismo en conjunto tuvo conexión con las problemáticas panamericanas más allá de las conflictivas relaciones que lo atravesaron (Morgenfeld, 2012). En el caso de las mujeres en particular, las Actas de Chapultepec fueron reivindicadas en los debates legislativos como antecedentes normativos de relevancia para promover derechos en el ámbito nacional (Valobra, 2010; de Gregorio Lavié, 1948, p. 1). Asimismo, la realización

30. Tal como ha señalado María Estela Spinelli (2005), durante el gobierno de Pedro E. Aramburu, "el peronismo como identidad política se definió como el enemigo del sistema democrático y de la nación misma, lo que no había sido así en la etapa anterior [con Lonardi], cuando se dijo oficialmente perseguir únicamente el delito. Esto imprimió dos rasgos distintivos a la nueva política porque, en primer lugar, tuvieron mayor coherencia los actos de gobierno referidos a este tema y, en segundo lugar, al asumir un decidido rol desperonizador, el gobierno negó cualquier intento de ser árbitro del conflicto peronismo-antiperonismo, como pareció haberlo intentado Lonardi, para asumirse como parte del mismo en condición de representante de los vencedores" (p. 75). 
de la Asamblea Extraordinaria de la CIM en Buenos Aires (1949) y con Evita como presidenta honoraria sirvió para la proyección política en el marco americano de las realizaciones del peronismo en materia de derechos políticos femeninos. Asimismo, con Elsa Alamán de Chamorro, abogada y dirigente peronista presidiendo la Asamblea, se reclamó desde allí la rúbrica de la Convención interamericana sobre la concesión de los derechos políticos a la mujer, establecida en 1948 que recomendaba la igualdad con los varones en esa materia. Es decir, la retórica de los organismos internacionales no fue ajena a la de las mujeres peronistas. De hecho, la sanción de la ley de derechos políticos de las mujeres durante el gobierno de Perón fue considerada una de las formas de sacar a las mujeres de la situación de atraso y esclavitud a la que las sometían las fuerzas conservadoras (Valobra, 2010).

Durante la etapa de la proscripción, con menor énfasis que el que tuvo en las discusiones en el radicalismo, hubo reclamos vinculados a la proyección partidaria de las mujeres y debates intergeneracionales sobre la formación política.

Pese a los discursos que observaban al peronismo como opuesto a la modernización política, para algunas peronistas, ello no fue así. La inserción en los espacios de participación promovidos entre 1946-1955 les posibilitó adquirir competencias para su desarrollo personal en el espacio público, tanto en lo político como en lo laboral ( Barry, 2009). ${ }^{31}$ Tal es así que Marta

31.Algunas mujeres así lo experimentaron: Entrevista a Saúl Buzeta (h) (hijo de Inés Dighian), realizada por Anabella Gorza, 11 de marzo de 2014 y Entrevista a Marta Doglione, realizada por Anabella Gorza, el 10 de diciembre de 2008.

144
Curone, ${ }^{32}$ conocida militante, observaba que, tras la Libertadora y en un contexto supuestamente modernizador, había restricciones para las peronistas. Sostenía que las mujeres de su generación, que por entonces rondaban los treinta años, no tenían tiempo para compatibilizar sus obligaciones privadas con el ejercicio de la política bajo un régimen de tipo liberal que las obligaba a estar pendientes de las actividades de subsistencia. Esta situación la consideraba contrastante con la que había experimentado bajo el gobierno peronista, $\mathrm{du}-$ rante el cual se le habían ofrecido a las mujeres oportunidades de salir "de su hogar para aportar sus conocimientos al engrandecimiento del país" ${ }^{33}$ En ello también coincidía la periodista y militante Nora Lagos. ${ }^{34}$ Ella señalaba la exclusión histórica sufrida por las mujeres respecto de las esferas sociales de relevancia como la política, la ciencia y la cultura, y su confinamiento al espacio doméstico. Frente a ello, reclamaba a los políticos que consideraran un horizonte más amplio para las mujeres:

El progreso colectivo ha experimentado un proceso lento, cuyo corolario fue la lenta evolución de la humanidad ¿La causa? El desdén hacia la mujer, obstaculizando su intervención en las actividades múltiples de la vida. Se le aisló en el hogar con el beneplácito de los antifeministas -que aún hoy abundan-, quienes, empero no se dieron

32. Era una dirigente de la Rama Femenina que hizo su ingreso a la política a través de la Unión de Estudiantes Secundarios (en adelante, UES), pasando luego a la Juventud Peronista (en adelante JP), para integrarse finalmente en 1959 a la conducción de la Rama Femenina del Partido Justicialista.

33. Carta de Marta Curone a Perón, 25 de julio de 1964. Archivo personal de Marta Curone (APMC).

34. Ex directora del diario La Capital de Rosario, y luego, de Soberania (1956-1958) y La Argentina (1955). Gorza (2015). 
cuenta que ella tenía en sus manos el arma más formidable: la formación espiritual y moral de los hombres (...) prohibiéndosele, en cambio, su intervención en la vida pública, científica, cultural, etc. ${ }^{35}$

El artículo señalaba la necesidad de que a las mujeres se les dieran mayores posibilidades de participación en la vida pública y entendía que su rol de educadoras de los varones no significaba que se las limitara a lo doméstico: "Entendemos que a la mujer moderna es necesario, urgentemente necesario, marcarle otro derrotero, si se quiere que ella como madre, ofrezca a las sociedades mayores y más benéficos frutos". ${ }^{36}$ En otro artículo, consideraba que la omisión de la problemática femenina atravesaba las ideologías políticas. ${ }^{37}$ Además de esa cuestión estructural, Lagos reflexionaba sobre la coyuntura de proscripción que vivía el peronismo y, en cuanto a las mujeres, señalaba que la ausencia de su voz en la política no se debía a su falta de interés en la misma o a no asumir las responsabilidades que les había otorgado el voto, idea que resonaba en los debates de la época, sino a la imposibilidad de participar y organizarse políticamente ante la proscripción del Partido Peronista Femenino. En ese sentido, rescataba que si bien "la formación política de la mayoría" era "de pocos años", entre esa mayoría" había habido, y todavía había, "mujeres para las cuales la política ocup[aba] un

35. Misión Trascendental de la Mujer Argentina (28 de diciembre de 1955). La Argentina 7, p. 2. Colección Mikielievich (CM) Archivo del Museo Histórico Provincial de Rosario “Dr. Julio Marc”(AMHPJM), Rosario.

36.Misión Trascendental de la Mujer Argentina (28 de diciembre de 1955). La Argentina 7, p. 2. CM, AMHPJM, Rosario.

37.La Mujer y la Patria (14 de enero de 1957). Soberania 5, p. 3. CM, AMHPJM, Rosario. lugar de importancia” desde hacía largos años $y$, en ese contexto, la patria las necesitaba expresando su voz.

En estos artículos no puede dejar de advertirse el lugar que la directora de los periódicos estaba reclamando para sí. Ello permite reflexionar acerca de cómo se posicionaron en el peronismo ciertas mujeres de extracción social media o alta, tales los casos de Curone y Lagos, respectivamente, que accedieron, aunque de manera limitada y aislada, a instancias donde pudieron expresarse públicamente. Las posibilidades que el peronismo abrió para ellas y las expectativas que volcaron en su participación política no se condicen con el lugar subordinado y manipulable que los discursos de otras fuerzas políticas solían atribuirle a la militancia peronista.

Entre las mujeres hubo quienes sostenían la necesidad de modernizar las prácticas y formas de organización en el partido. Esas propuestas surgieron de una evaluación endógena de las propias experiencias. Desde las elecciones de febrero de 1958 que consagraron el triunfo de Frondizi, no faltaron iniciativas de las mujeres por reorganizar la Rama Femenina -nombre que había adquirido el PPF desde la reforma partidaria de 1954. Sin embargo, en un contexto proscriptivo y sin la presencia de Eva Perón, esas iniciativas encontraron muchos obstáculos. El principal problema estuvo vinculado a la imposibilidad de sustraerse a las luchas facciosas y a la intromisión del poder masculino sindical y político partidario- sobre decisiones que en el pasado hubieran concernido exclusivamente a las mujeres. No puede hablarse para la época de una Rama Femenina centralizada. La presencia de mujeres en el Consejo Coordinador, máxima estructura política, implicaba que la Rama Femenina tuviera representación 
en ella, pero no que estas dirigentes tuvieran injerencia sobre las mujeres que a lo largo de todo el país desarrollaban su militancia en las unidades básicas. Su prestigio derivaba de la trayectoria previa como delegadas censistas o legisladoras y no de una base de apoyo partidaria. A diferencia de la rama masculina donde se habían creado núcleos de poder regionales, ello no ocurrió entre las mujeres, producto de la estructura verticalista que Evita le había conferido al PPF (Barry, 2009). Esta característica influyó decisivamente en el resultado infructuoso que tuvieron los intentos de reorganización partidaria femenina tras el golpe (Gorza, 2017). Sin embargo, en la época, no faltaron voces que adjudicaron dichos resultados a la falta de capacitación política y organización, dos pilares del discurso modernizador sobre la participación política femenina. No es casual que este diagnóstico y sus consecuentes propuestas provinieran de mujeres que habían hecho su ingreso a la política durante el segundo gobierno peronista, en estructuras anudadas a la posibilidad de estudiar y de generar espacios de socialización que combinaran ambas esferas; como la UES y la JP.

Durante la época de la proscripción, se discutió quiénes debían ejercer la dirigencia y encabezar la reorganización: las mujeres $\mathrm{cu}^{-}$ yos liderazgos se habían forjado en las luchas de la resistencia al gobierno de la Revolución Libertadora o aquellas que habían dirigido el viejo PPF. La disputa se saldó en favor de estas últimas, en especial de Delia Parodi, quien había ejercido el cargo de secretaria general de la Rama Femenina desde $1954 .{ }^{38}$ También, se

38. Lo había desempeñado de hecho desde 1952, al asumir como delegada del Partido en Capital Federal, luego de la muerte de Eva (Barry, 2009). Estas disputas se entablaron sobre todo en el Comando Táctico - primera estructura que intentó reorganizar institucionalmente criticó la injerencia de los dirigentes políticos y sindicales masculinos sobre la reorganización de la Rama y se disputaron lugares en los organismos de conducción y listas electorales. Curone señalaba la discriminación que sufrían las mujeres en el peronismo por parte de la dirigencia masculina, que les ponía barreras para acceder a cargos de conducción y para obtener niveles de representación equitativos. Así lo expresaba en la Asamblea Interpartidaria Femenina:

E1 Poder Ejecutivo convertido en autoritario legislador, por obra y gracia de los magos de la política, no sólo interviene en los derechos inalienables de los ciudadanos, sino que sojuzga las propias organizaciones cívicas existentes a las que trata en forma inquisitorial.

Pero también los partidos políticos están en crisis, porque no se adecúan a la realidad histórica (...) aún hoy cierran sus puertas a cualquier pretensión de elevar a la mujer a un plano de igualdad con respecto al hom-

al peronismo proscripto. En septiembre de 1958 se creó el Consejo Coordinador y Supervisor del Movimiento Peronista, luego, del Partido Justicialista. En esa estructura, de un total de quince miembros, sólo tres eran mujeres y todas provenientes del PPF: Delia Parodi, Ceferina Rodríguez de Copa y María Elena Solari de Bruni. En 1962 hubo una reestructuración del Consejo, pasando a estar constituido por siete mujeres, encabezadas por Delia Parodi. La mayor presencia la tuvieron las representantes del PPF; además de Delia, se encontraban Nélida de Miguel, Zelmira D’Estéfano y Solari de Bruni. Las otras tres eran Leonor Von Wernick -representante de la Resistencia -, y Marta Curone y Haydée Pesce, que provenían de la UES. Hacia fines de 1963, Perón designó una Comisión Interventora o Cuadrunvirato, donde hubo una mujer, Hilda Pineda de Moulins, electa senadora nacional en 1954; aunque la máxima referente de la Rama Femenina continuó siendo Delia Parodi hasta su expulsión en 1966. Disponible en: Curone (s/f). Mimeo. APMC, consultado en Buenos Aires, en 2016. 
bre en el desempeño de cargos públicos. La mujer sigue disminuida a pesar de que efectúa idénticas funciones en fábricas, empleos y universidades y de que esposa y madre, tiene tiempo para buscar otras ocupaciones y estudios que la enaltecen y redundan en beneficio de su familia ${ }^{39}$

La formación política fue considerada una herramienta necesaria para defender la autonomía de dicha rama. Desde el boletín Conquista, que editaba Curone, se instaba a las mujeres a organizarse y capacitarse a la vez que se proponían estrategias concretas de ordenamiento con el objetivo de que pudieran disputar cargos políticos: "Organizadas lograremos ser respetadas y podremos desempeñar así un papel clave en las futuras decisiones nacionales. Sujetas a las reacciones hepáticas del dirigente de turno quizás no logremos pasar de la sala de espera de los postulantes". ${ }^{40}$ La capacidad organizativa, la educación y la formación política actuaron como elementos legitimadores que las nuevas dirigentes pretendieron hacer valer ante las antiguas y ante los varones. ${ }^{41}$ Hubo, también, debates intergeneracionales en los que se cuestionaron las viejas formas de hacer política y procurando modernizar a la Rama Femenina. La propia Curone sostenía que para lograr la reorganización partidaria era necesaria la formación política y convocaba a las mujeres a cursos de oratoria. Los mis-

39. Discurso de Marta Curone en la Asamblea Interpartidaria Femenina, 18 de julio de 1962. APMC.

40. Continuidad para la Rama Femenina (20 de febrero de 1964). Conquista 3, p. 3. APMC.

41. Diana Pareja se quejaba con Perón de las viejas dirigentes que limitaban a las nuevas surgidas en los años de la proscripción, en especial, la ex legisladora Nélida De Miguel, quien, según Pareja, solía manifestar que las mujeres que estudiaban no debían dirigir el Partido. Carta de Diana Pareja a Perón, 26 de febrero de 1964. APMC. mos implicaban el aprendizaje de técnicas de improvisación y memoria, la presentación de breves trabajos sobre cuestiones doctrinarias y el comentario de temas de actualidad. ${ }^{42} \mathrm{La}$ intención era que las mujeres se interesaran sobre los temas de la coyuntura política y adquirieran conocimientos y competencias que les permitieran disputar espacios de poder. Era un cambio respecto de la formación a partir de temas concretos que se realizaba en las unidades básicas durante el gobierno de Perón (Barry, 2009).

Durante el breve gobierno de José María Guido (1962-1963), en el marco de lo que se conoció como "el giro a la izquierda del peronismo", hubo acercamientos interpartidarios en pos de objetivos comunes entre las mujeres. Principalmente, se dieron en la conformación de una Comisión Interpartidaria Femenina (1962), convocada por el Partido Comunista y que incluyó a mujeres de un amplio espectro político -del Partido Socialista Argentino de Vanguardia, de la Intransigencia Radical de la UCRP y del Movimiento Popular Argentino; y continuaron, en menor medida, durante el gobierno de Arturo Illia. Entonces, algunas peronistas participaron en el Congreso de Mujeres de la Habana (1963), vinculado a la FDIM, y otras viajaron a la URSS. En este contexto, se hicieron algunas peticiones conjuntas. ${ }^{43}$ Las pero-

42. Primer Curso Femenino de Oratoria (20 de febrero de 1964). Conquista 3, p. 2. APMC.

43. Los sectores femeninos de cinco partidos unidos en su acción (31 de julio de 1962). Nuestra Palabra, p. 3. Archivo del Partido Comunista de Argentina (APCA). Sede Central del Partido Comunista de Argentina, Buenos Aires; Unidas contra la carestía (21 de agosto de 1962), Nuestra Palabra. APCA, Buenos Aires; UMA impulsa las luchas de las mujeres (2 de octubre de 1962). Nuestra Palabra, APCA, Buenos Aires; Comisión Interpartidaria Femenina de Córdoba (9 de octubre de 1962). Nuestra Palabra, APCA, Buenos Aires; 
nistas que participaron de estas instancias de cooperación, las interpretaron como positivas en tanto permitían dar a conocer la obra del peronismo en el extranjero, además del aprendizaje político que favorecían. ${ }^{44}$

En síntesis, la etapa de la proscripción no benefició a las peronistas, que vieron limitada su representación en los órganos de conducción del Partido Justicialista frente al poderío que había adquirido el sindicalismo sobre la estructura política, a la vez que no quedaron exentas del proceso centrífugo que atravesó al peronismo durante esos años. Sin embargo, no puede pasarse por alto cómo algunas de ellas se vieron interpeladas por algunas de las dimensiones de esos discursos de los organismos internacionales. En particular, la de la formación política y necesidad de educación cívica. Estas fueron un aliciente para cuestionar las propias prácticas en el peronismo y su necesidad de transformación, poniendo en evidencia su papel de agencia en contra de las interpretaciones de docilidad que solía atribuírseles en la época y que ha primado en algunas interpretaciones historiográficas.

Impresiones de la Unión Soviética de una dirigente peronista (8 de noviembre de 1962), Nuestra Palabra, APCA, Buenos Aires; Dirigente peronista Blanca Vázquez aclara su situación (1 de enero de 1963). Nuestra Palabra, p. 6. APCA, Buenos Aires; Congreso Nacional de Mujeres (9 de diciembre de 1964). Nuestra Palabra. p.3. APCA, Buenos Aires; Curone, M. (s/f). "El Primer Congreso de Mujeres de América. Cuba. 5 al 10 de enero de 1963", en Al servicio de la causa (Capítulo sin publicar). APMC.

44. Curone, M. (s/f). "El Primer Congreso de Mujeres de América. Cuba. 5 al 10 de enero de 1963”. Al servicio de la causa. Mimeo. APMC.

\section{Consideraciones finales}

En este artículo, hemos realizado un primer ejercicio que repone la necesidad genuina de reconsiderar un período usualmente vinculado a la modernización social, desde una perspectiva de género. Frente a los estudios que han abordado la problemática atendiendo a transformaciones ocurridas en el nivel de la vida cotidiana y el mundo cultural, hemos procurado reconstruir prácticas partidarias e institucionales, bajo el prisma de aspectos propios de la política y lo político.

En el contexto bajo estudio, las mujeres fueron un sujeto político en disputa que, no obstante, ha merecido escasas referencias. El período se caracterizó por una decidida intervención de los organismos internacionales en torno a la transformación de la condición de las mujeres cuya situación menguada en materia de derechos y de acceso efectivo a los mismos fue visualizada como parte de una herencia de retraso y subdesarrollo que debía llegar a su fin.

De allí, reflexionamos sobre dos ámbitos de análisis que se interrelacionaron, el internacional (considerando organismos internacionales) $y$ el nacional (tanto en un nivel gubernamental como partidario). Para ello, reconstruimos el vocabulario específico con que aparecieron estas cuestiones en los debates contemporáneos y más allá de las formas en las que la bibliografía las conceptualizó. Mientras lo moderno y la modernidad fueron categorías nativas, la noción de modernización política no integró el vocabulario de manera expresa, pero fue una invitación a abandonar las prácticas atávicas que caracterizaban a la sociedad y a la política.

Estas tendencias internacionales fueron un horizonte que formó parte del clima de época. 
Ello se pone de manifiesto en la estrecha relación que tuvieron las dependencias gubernamentales para mujeres y dirigidas por mujeres con organismos internacionales. No obstante, como hemos demostrado, algunos gestos institucionales que pueden ser hitos relevantes en esta historia, no tuvieron los alcances e impactos que esos mismos organismos esperaban. Parte del problema puede comprenderse si tenemos en cuenta la lógica de funcionamiento de esos organismos internacionales. En efecto, éstos promovían a las mujeres como colectivo que necesitaba educarse y capacitarse cívicamente para alcanzar puestos legislativos, ejecutivos, etcétera. Pero esa identificación de sus necesidades y la exigencia de su formación política y profesionalización, no iban acompañadas de consideraciones sobre el sistema político nacional de los Estados a los que iban dirigidos esos lineamientos. De esa manera, se festejaba la sanción de leyes de derechos políticos para las mujeres a la vez que no se problematizaban los contenidos y contextos de su realización. Tal es así que se escindían esos derechos de sus contextos de posibilidad y se exigía, a través de indicadores generales, expectativas de logro extrañas o difíciles de sostener en esos países. Por caso, los organismos internacionales consideraban que obtenidas las leyes y propiciada la formación de las mujeres, su proyección política sería su consecuencia automática. Sin embargo, no reflexionaban, específicamente, sobre los medios que se podían interponer para esa consecución: la proscripción de partidos políticos, la existencia de dictaduras, las relaciones interpartidarias no sólo de competencia sino también de colaboración o -incluso en sistemas que se parecieran a esas democracias que se idealizaban- el papel de los propios partidos políticos que obturaban con sus culturas excluyentes la proyección de las mujeres.
En Argentina, esa agenda de intervención que hace de la participación política uno de sus arietes, se vio atravesada por un intento de desmovilización de los sectores que se consideraba que atentaban contra ese objetivo de democracia liberal, en particular, el peronismo. En ese interjuego de fuerzas, los resultados implicaron lógicas superpuestas, contradictorias, complementarias. Así, la modernización política se perfiló como un horizonte en el que las mujeres alcanzarían un reconocimiento basado en una igualdad pública de derechos, pero sin horadar la supuesta especificidad que ellas portaban como tales. La paridad exigida por las normas internacionales en cargos ejecutivos $\mathrm{y}$ de representación durante las gestiones radicales no se alcanzó. El empuje para el ingreso a la política de mujeres modernas privilegió a quienes tuvieran competencias profesionales -y en ese sentido, fue claramente excluyente-. Para quienes no las tuvieran, la formación política y la educación cívica fueron bastiones que a futuro darían frutos tanto en relación con su incursión en puestos directivos o representativos como en la emisión del voto. Ninguna paridad se dio en los cargos partidarios, aunque las peronistas, incluso en el contexto de la proscripción, obtuvieron algunos lugares.

Como un primer intento de sopesar la incidencia de las recomendaciones internacionales en Argentina, hemos repuesto las propias trayectorias partidarias y las experiencias nacionales. Para ello, además de analizar la retórica, hemos definido intervenciones específicas que las mujeres realizaron teniendo en cuenta ciertos elementos de aquellas discusiones internacionales. Primero, es importante destacar que esos discursos internacionales impactaron sobre procesos endógenos propios y los nutrieron, pero no fueron los únicos, aunque aquí los hayamos privilegiado para nuestra reflexión. 
En ese sentido, un aspecto a destacar en esa resignificación, es cómo las mujeres radicales (intransigentes y del pueblo) insistieron en su promoción intrapartidaria. Esto es interesan$\propto \tilde{\ell} \propto$ te teniendo en cuenta que el radicalismo, aún con un número importante de mujeres en sus filas, no había sido propenso en su historia a promocionarlas en cargos dirigentes o electivos. Por otra parte, durante los gobiernos peronistas se había impulsado esa actuación, aunque no sin conflictos. La amplitud en sus actuaciones fue considerada por el antiperonismo como carente de la formación política adecuada. Sin embargo, este fue también un reclamo de algunas de las nuevas generaciones de mujeres peronistas durante la etapa de la proscripción. De manera concurrente, tanto radicales como peronistas se enfocaron en la importancia de la formación política para la actuación femenina en los partidos, sindicatos y otras instancias políticas y, asimismo, una redefinición del sujeto de ciudadanía en relación con la representación y la gestión.

En este primer desbroce del terreno, antes que calificar el proceso histórico bajo estudio como modernización política nos hemos concentrado en delimitar la transformación y dimensiones exaltadas. ${ }^{45}$ Así, hemos comenzado a señalar la relevancia de considerar las estructuras de género que no se han conmovido en la medida de las exigencias que los propios grupos políticos bajo estudio pusieron como estándar de modernización y camino insoslayable para la democratización que estipularon.

45. Retomamos la idea de Andrew Appeton y Amy Manzur (1993) que han analizado para Francia un fenómeno semejante, intentando constatar los indicadores elaborados para testear lo que ha dado en llamarse modernización política y han expuesto que la problemática entre la retórica y la realidad, difícilmente pueda constatarla. 


\section{Referencias bibliográficas}

Acha, O. (2012). Un revisionismo bistórico de izquierda y otros ensayos de politica intelectual. Buenos Aires: Herramienta.

Altamirano, C. (1998). Desarrollo y desarrollistas. Prismas. Revista de historia intelectual, (2), 75-94.

Ansaldi, W. y Giordano, V. (2012). América Latina. La construcción del orden. Buenos Aires: Ariel.

Appeton, A. y Manzur, A. (1993). Transformation or Modernization: The rethoric and reality of gender and party politics in France. En J. Lovenduski y P. Norris, Gender and Party Politics (pp. 87 a 112). London: Sage publications.

Barrancos, D. (2007). Introducción. En Primer Congreso Femenino, Buenos Aires 1910, Historia, Actas y Trabajos (pp. 2019-220). Córdoba: Universidad Nacional de Córdoba.

Barry, C. (2009). Evita Capitana. Buenos Aires: Eduntref.

Beigel, F. (2006). Vida, muerte y resurrección de las “teorías de la dependencia”. En Autor (Ed.), Crítica y Teoría del pensamiento social latinoamericano (pp. 287-326). Buenos Aires: Consejo Latinoamericano de Ciencias Sociales. Recuperado de http://biblioteca.clacso.edu.ar/clacso/becas/20140227054137/C05FBeigel.pdf

Bianchi, S. (1986). Peronismo y Sufragio Femenino: la ley electoral de 1947. Anuario IEHS, (1), 255-296. Recuperado de http://anuarioiehs.unicen.edu.ar/Files/1986/009\%20-\%20Bianchi,\%20Susana\%20 -\%20Peronismo\%20y\%20sufragio\%20femenino,\%201a\%20ley\%20electora1\%20de\%201947.pdf

Blanco, A. (2003) Política, modernización y desarrollo: una revisión de la recepción de Talcott Parsons en la obra de Gino Germani. Estudios Sociológicos, 21(63), 667-699.

Blanco, A. y Jackson, L. (2017). "Jefes de escuela" en la sociología latinoamericana: Gino Germani, Florestan Fernandes y Pablo González Casanova. México: Sociológica.

Cavarozzi, M. (1982). El 'Desarrollismo' y las relaciones entre democracia y capitalismo dependiente en 'Dependencia y Desarrollo en América Latina'. Latin American Research Review, 17(1), 152-165. Recuperado de https://www.jstor.org/stable/pdf/2502946.pdf

Cichero, M. (1992). Cartas Peligrosas. La apasionada discusión entre Juan Domingo Perón y el padre Hernán Benitez sobre la violencia politica. Buenos Aires: Planeta Espejo de la Argentina.

Comisión Interamericana de Mujeres (1960). Informe presentado a la Decimocuarta Reunión de la Comisión de la Condición Jurídica y Social de la Mujer de las Naciones Unidas. Washington: Unión Panamericana.

Cosse, I. (2014). Mafalda: historia social y politica. Buenos Aires: Fondo de Cultura Económica. 
Cosse, I., Felitti, K. y Manzano, V. (Coords.) (2010). Los '60 de otra manera. Vida cotidiana, género y sexualidades en la Argentina. Buenos Aires: Prometeo.

Curone, M. Al servicio de la causa, mimeo.

De Gregorio Lavié, L. (1947). Trayectoria de la condición social de las mujeres argentinas. Santa Fe: Universidad Nacional del Litoral.

De Gregorio Lavié, L. (1948). La ciudadana, Buenos Aires: s/e.

Feijóo, M. y Nari, M. (1996). Women in Argentina during the 1960's. Latin American Perspectives, 23(1), pp. 7-26.

Felitti, K. (2012). La revolución de la píldora. Natalidad y politica en la Argentina de los sesenta. Buenos Aires: Edhasa.

Gallo, E. (2000). Las mujeres en el radicalismo argentino. Buenos Aires: Eudeba.

Giordano, V. (2012). Ciudadanas Incapaces. La construcción de los derechos civiles de las mujeres en Argentina, Brasil, Chile y Uruguay en el siglo XX. Buenos Aires: Teseo.

Gorza, A. (2016). La militancia femenina en la Resistencia peronista a través de la prensa opositora (19551958). Nora Lagos y los periódicos La Argentina y Soberanía. Revista de Historia Americana y Argentina, 51(1), 131-167. Recuperado de http://revistas.uncu.edu.ar/ojs/index.php/revihistoriargenyame/article/ view/1243/809

Gorza, A. (2017). Insurgentes, misioneras y politicas. Un estudio sobre mujeres y género en la Resistencia peronista (1955-1966) (Tesis doctoral inédita). Universidad Nacional de La Plata, Argentina. Recuperada de http://sedici.unlp.edu.ar/handle/10915/61210

Graciarena, J. (1976). Poder y estilos de desarrollo, una perspectiva heterodoxa. Revista de la CEPAL, 173193. Recuperado de https://repositorio.cepal.org/bitstream/handle/11362/12289/001173193_es.pdf? sequence $=18$ is Allowed $=y$

Haan, F. (2010). Continuing Cold War Paradigms in the Western Historiography of Transnational Women's Organizations: The Case of the Women's International Democratic Federation (WIDF). Women's History Review, 19(4), 547-573.

Henales, L. y Del Solar,J. (1993). Mujer y política: participación y exclusión (19551966). Buenos Aires: CEAL.

Htun, M. (2003). Sex and the State: Abortion, Divorce, and the Family under Latin American Dictatorships and Democracies. Cambridge: University Press.

Huntington, S. (1966). Political Modernization: America vs. Europe. World Politics, 18(3), 378-414.

Latour, B. (2016). Si nunca fuimos modernos ¿Qué nos pasó? Cuadernos de Antropología Social, (43), 17-19. Recuperado de http://revistascientificas.filo.uba.ar/index.php/CAS/article/view/2993/2624 
Lobato, M. (2003). María Eva Duarte de Perón. Evita (1919-1952). Madrid: Ediciones del Orto.

Manzano, V. (2010). Ha llegado la 'nueva ola': música, consumo y juventud en la Argentina. En I. Cosse, K. Felitti y V. Manzano (Coords). Los '60 de otra manera. Vida cotidiana, género y sexualidades en la Argentina (pp. 19-60). Buenos Aires: Prometeo.

Miller, F. (1991). Latin American Women and the Search for Social Justice. Hanover: University Press.

Morgenfeld, L. (2012). Vecinos en conflicto. Buenos Aires: Peña Lillo.

Navaith, F. (2000). El modelo soviético. En G. Duby y M. Perrot (Dirs.). Historia de las Mujeres. Siglo XX (pp. 257-290). Madrid: Taurus.

O’Donnell, G. (1982). El estado burocrático autoritario: 1966-1973. Triunfos, derrotas y crisis. Buenos Aires: Editorial de Belgrano.

Portantiero, J. (1973). Clases dominantes y crisis política de la Argentina actual. En Brown, O. (Comp.). El capitalismo argentino en crisis. Buenos Aires: Siglo XXI.

Pye, Lucien W. (1979). Political Modernization: Gaps between Theory and Reality. The Annals of the American Academy of Political and Social Science, 442(1), 28-39.

Spinelli, M. (2005). Los vencedores vencidos. El antiperonismo y la "revolución libertadora". Buenos Aires: Biblos.

Stábile, B. (1961). La mujer en el desarrollo nacional. Buenos Aires: Ediciones Arayú.

Stavenhagen, R. (1981). Sociología y Subdesarrollo. México: Nuestro Tiempo.

Towns, A. (2010). The Inter-American Commission of Women and Women's Suffrage, 1920-1945. Journal of Latin American Studies, 42(4), 779-807.

Valobra, A. (2010). Del hogar a las urnas. Recorridos de la ciudadanía política femenina. Argentina, 1946-1955. Rosario: Prohistoria.

Valobra, A. (2013). Participación de la mujer en la vida pública. Notas sobre el Seminario Nacional de 1960. Cuadernos de h ideas, 7(7), 1-18. Recuperado de https://perio.unlp.edu.ar/ojs/index.php/cps/article/view/2054

Valobra, A. y Yusta Rodrigo, M. (2017) (Eds.). Queridas Camaradas. Historias iberoamericanas de mujeres comunistas, 1935-1975. Buenos Aires: Miño y Dávila.

Valobra, A. (en prensa). Las argentinas en el concierto de las naciones: de las Guerras Mundiales a la Guerra Fría. En Rodríguez Sáenz, E. (Ed.), Ciudadanas de la Guerra Fría en América Central (1945-1970): Perspectivas transnacionales. Costa Rica: Editorial de la Universidad Estatal a Distancia. 